\title{
Validation of a food frequency questionnaire to assess folate intake of Dutch elderly people
}

\author{
Ondine van de Rest $^{1,2}$, Jane Durga ${ }^{1,2}$, Petra Verhoef ${ }^{1,2}$, Alida Melse-Boonstra ${ }^{1,2}$ and Henny A. M. Brants ${ }^{3}$ \\ ${ }^{1}$ Division of Human Nutrition, Wageningen University, Wageningen, The Netherlands \\ ${ }^{2}$ Wageningen Centre for Food Sciences, Wageningen, The Netherlands \\ ${ }^{3}$ TNO Quality of Life, Zeist, The Netherlands
}

(Received 5 December 2006 - Revised 29 March 2007 - Accepted 3 April 2007)

Folate is required for 1-carbon metabolism and deficiency in folate leads to megaloblastic anemia. Low levels of folate have been associated with increased risk of vascular disease. To investigate whether RDA of folate are met, habitual folate intake needs to be assessed reliably. We developed a FFQ to specifically measure folate intake over the previous 3 months in elderly people in the Netherlands. Major sources of folate intake, i.e. foods contributing to at least $80 \%$ of the average folate intake, were identified through an analysis of the second Dutch Food Consumption Survey for the sub-population of men and women aged 50-70. In 2000 and 2001, folate intake was estimated with this questionnaire in 1286 individuals aged 50-75 years. Concentrations of serum and erythrocyte folate served as biomarkers with which relative validity of the questionnaire was assessed. The same FFQ was repeated after 3 years in 803 subjects in order to assess long-term reproducibility. Mean folate intake was estimated to be 196 (SD 69) $\mu \mathrm{g} / \mathrm{d}$. Spearman correlation coefficients between folate intake and serum and erythrocyte concentrations were $0.14(P<0.01)$ and $0.05(P=0.06)$ respectively. Spearman correlations between folate intakes measured at baseline and after 3 years were $0.58(P<0.01) .47 \%$ of the participants were classified in the same quartiles on the two occasions. Our FFQ showed a weak correlation between folate intake and blood folate concentrations and reproducibility was acceptable. This FFQ is able to rank subjects according to their folate intake.

FFQ: Folate intake: Biomarkers: Validity: Reproducibility

Folate is a B vitamin that is essential for many aspects of human health. Deficiency of this B vitamin can lead to megaloblastic anemia ${ }^{1}$. A suboptimal folate status can increase the risk for women to have a child with a neural tube defect $^{2}$. Furthermore, low folate status and subsequent elevated concentrations of plasma total homocysteine (tHcy) have been associated with neurocognitive dysfunction ${ }^{3}$, colon cancer ${ }^{4}$ and vascular diseases 5 . Folate is found in foods such as liver, vegetables, bread, potatoes, dairy products and fruit ${ }^{6}$. In the Netherlands, the RDA of folate is $300 \mu \mathrm{g}$ for adults ${ }^{7}$. However, many Dutch adults do not meet this recommendation 6 .

There are different methods to assess habitual nutrient intake, but so far there is no gold standard. In large-scale epidemiological studies FFQ are preferred, because they are easy to administer and measure long-term intake. We developed a FFQ to assess folate intake over the past 3 months in Dutch elderly people. Here we describe the development of this questionnaire and subsequent comparison of the folate intake data with blood folate concentrations to assess the validity of the questionnaire. Furthermore long-term reproducibility was assessed.

\section{Subjects}

Baseline data of subjects from three different folate supplementation studies undertaken by our group in the past years were combined: (1) The FACIT-study ${ }^{8}$, a double blind, randomised, placebo-controlled intervention study on the effect of 3 years supplementation with $0.8 \mathrm{mg}$ folic acid/d on age-related diseases (carotid artery intima-media thickness, cognitive function and hearing); (2) the Dolfin-study ${ }^{9}$, a doseresponse trial with a randomised, double blind, parallel-group, placebo-controlled design aiming to find the lowest dose of folic acid that maximally lowers tHcy concentrations, and (3) the CHEF-study ${ }^{10}$, a placebo-controlled, randomised parallel trial to study relative bioavailability of polyglutamated folic acid $v$. monoglutamated folic acid. The study populations consisted of 819, 308 and 182 subjects, respectively. Twentythree subjects participated in Dolfin as well as in CHEF. We decided to use their data from Dolfin, as in Dolfin MTHFR genotypes, which influence folate status, have also been determined. Five subjects were excluded from further analyses because of missing values on the FFQ. Altogether, complete data of 1281 subjects (861 men, 425 women) were available 
for analysis. Furthermore, the FFQ was administered for a second time after 3 years in 803 subjects in the FACITstudy, allowing us to study long-term reproducibility.

Subjects from all three studies were recruited from local blood banks and municipal registries in Wageningen and surroundings. Men and post-menopausal women aged 50-70 years (Dolfin $<76$ years) were eligible for the studies. Inclusion criteria for all studies were: (1) women's last menstruation had to be longer than 2 years ago and if the uterus was removed they had to be older than 55 years; (2) no thyroid or renal disease; (3) no use of medication that affects folate metabolism and no use of supplements containing folic acid, vitamin $\mathrm{B}_{6}$ or vitamin $\mathrm{B}_{12}$; (4) thcy levels had to be $<26 \mu \mathrm{mol} / \mathrm{l}$. For the FACIT-study additional inclusion criteria were: no use of medication that might affect carotid artery intima-media thickness (e.g. lipid-lowering drugs or hormone replacement therapy), tHcy concentrations $>13 \mu \mathrm{mol} / \mathrm{l}$, serum vitamin $\mathrm{B}_{12} \geq 200 \mathrm{pmol} / \mathrm{l}$ and compliance during a 6-week run-in period $\geq 80 \%$. Additional inclusion criteria for Dolfin and CHEF were: serum vitamin $\mathrm{B}_{12}>160 \mathrm{pmol} / \mathrm{l}$ and serum creatinine concentrations $<125 \mu \mathrm{mol} / \mathrm{l}$. The Medical Ethical Committee of Wageningen University approved all research protocols, and all subjects gave written informed consent.

\section{Methods \\ Development of the FFQ on folate}

The FFQ was developed in 2000 with goals to describe the habitual mean intake of folate at population level in the previous 3 months and to be able to classify individual subjects based on their habitual daily folate intake. Major dietary sources of folate intake in the elderly Dutch population were identified through an analysis of the second Dutch Food Consumption Survey (VCP2, 1992) for the sub-population of men and women aged 50-70 (n 1278) ${ }^{11}$. Folate calculations were made using the table of folate contents in food from 1995 compiled by Brants and Hulshof ${ }^{12}$. This folate table was mainly based on data originating from the British food composition table ${ }^{13}$ and some other international food tables, for which analyses were mainly done by microbiological assay. Because new Dutch folate content data obtained with HPLC became available in $2001^{6}$, old and new data were compared to see if the selection of relevant food (group)s had to be changed. Based on these new folate content data, the average total folate intake was $27 \%$ lower than the average folate intake based on the old folate content data of the table from 1995. This resulted mainly in a lower contribution of potatoes and milk to folate intake, whereas the contribution of meat and meat products was higher according to the new table ${ }^{14}$. The correlation between the folate contents of the two tables was 0.93 .

Calculations were performed for food groups at three levels of detail (e.g. vegetables; raw vegetables; raw carrots). The following variables were calculated and used for assessment of the relevance of food groups to folate intake and the necessary details: $\%$ contribution to folate intake of food groups calculated for the total population including non-users; $\%$ users of food groups; \% 'product-folate-users' i.e. \% of the total population that consumes folate from the particular food group; \% contribution to folate intake of food groups calculated for the product-folate-users only.
The first variable was used for the selection of the most important food groups that contribute to the folate intake at population level. The latter three variables were used for selection of food groups that are of minor importance on average level, but may contribute relevant amounts in the diet of some segments of the population. Within a food group we also considered the folate contents per 100-g product of the separate food products. When there was a large variation we made subgroups based on the content or picked out individual foods. The main food groups that contributed to the folate intake at population level were (in descending order): vegetables $(24.6 \%)$, bread $(17.7 \%)$, potatoes $(12.8 \%)$, milk and milk products $(11.2 \%)$, fruit $(6.1 \%)$, meat, meat products and poultry $(5.2 \%)$ and cheese $(5.0 \%)$. The complete list of selected foods, calculated over the total population, contributes to at least $80 \%$ of the average folate intake. Based on the more recent Dutch folate data, the contribution is probably somewhat higher, because the selection is extended with products that have higher folate contents according to the new data.

Furthermore, the questionnaire was extended with some questions to estimate total meat and fish consumption per meal type, some food items that are known to affect tHcy in the blood (coffee, tea and alcoholic beverages), and some questions to determine the general meal pattern (dietary regimens, vegetarianism, number of persons at dinner, number of dinners per week).

\section{$F F Q$}

The FFQ assessed the habitual consumption of eighty-nine food items in the previous 3 months. Subjects indicated their average consumption frequency of each food item by checking 1 of 10 frequency categories ranging from 'seldom or never' to '7 days a week'. For several foods additional questions were asked about the specific types or brands consumed and preparation methods. Since many specific vegetables, fruits and alcoholic beverages were asked for, chances of getting an overestimation of these foods (and therefore also of folate intake) were high. Therefore, total vegetable, fruit and alcohol consumption were also asked for in order to provide the possibility to check for inconsistencies and if necessary to correct the reported frequencies in a data- cleaning step. In the FACIT-study, any inconsistency was first reviewed with the subject in order to correct it prior to data entry.

Portion sizes were asked for in natural units (e.g. number of apples, slices of bread), household units (glasses, spoons, etc.) or grams (e.g. grams of meat). Grams per natural or household unit were mainly derived from a commonly used Dutch database $^{15}$.

For the development of the questionnaires Vofrex was used, a software package used for the development of $\mathrm{FFQ}^{16,17}$. With this program definitions of the questions were made that are required for data cleaning and calculation of folate intakes from the questionnaires in SAS Vovris, a software package for the processing of questionnaires ${ }^{18}$. Calculations were made using the computerised Dutch Food Composition Table $^{19}$.

Data were collected in 2000 and 2001. For the FACIT-study the FFQ was administered for a second time in 2003 and 2004, after a time interval of 3 years, when subjects had stopped taking the supplements. These data were used to evaluate 
the reproducibility of the questionnaire. At baseline as well as after 3 years subjects of the FACIT-study visited our research unit in two consecutive weeks; at their first appointment they received the FFQ and completed it at home; at their next appointment they handed it in and had it checked for completeness and consistency by a trained research assistant in a standardised way. Two independent dietitians performed double data entry. The questionnaires of the Dolfin- and the CHEFstudy were not reviewed by a dietitian or research assistant and data were only entered once. For all questionnaires the data-cleaning procedure of Vovris was used. The data-cleaning procedure checked for missing values, inconsistencies, values below the minimum or above the maximum intake and unknown alternatives and was conducted before calculations were made. Erratic values were checked again, and if necessary, corrections were performed.

\section{Other measurements}

To assess the BMI weight was determined using an electronic weighing scale to the nearest $0.1 \mathrm{~kg}$ and height was measured to the nearest $0 \cdot 1 \mathrm{~cm}$. We took fasting venous blood samples at the start of the intervention period of each study.

\section{Laboratory procedures}

Blood samples for determination of tHcy and erythrocyte folate were drawn into EDTA-containing evacuated tubes. Samples were immediately placed on ice and the plasma was separated from blood cells within $30 \mathrm{~min}$. Blood used for the determination of serum vitamin $B_{12}$, serum creatinine and serum folate was collected in serum separator tubes, which were placed in the dark and stored at room temperature for at least $30 \mathrm{~min}$ before centrifugation at $4^{\circ} \mathrm{C}$ for $20 \mathrm{~min}$ at $2000 \mathrm{~g}$ (FACIT samples) and for $10 \mathrm{~min}$ at $2600 \mathrm{~g}$ for the other samples. All samples were stored at $-80^{\circ} \mathrm{C}$. Concentrations of tHcy were measured by HPLC with fluorimetric detection at the Division of Human Nutrition, Wageningen University. Folate concentrations in serum and in erythrocytes as well as serum vitamin $B_{12}$ concentrations were determined with a commercial chemiluminescent immunoassay analyzer (Immulite 2000, Diagnostic Products Company, Los Angeles, CA, USA) at the clinical laboratory of the University Medical Centre, Nijmegen. The samples for erythrocyte folate analysis were further diluted with a concentrated human protein-based matrix (Immulite 2000 diluent) before measurement. Creatinine concentrations were measured with a kit (DuPont Dimension, Boston, MA, USA; Dade BV, Leusden, The Netherlands) based on the kinetic Jaffé reaction. DNA was isolated from whole blood. The MTHFR $677 \mathrm{C}>\mathrm{T}$ genotype was determined by PCR of genomic DNA and restriction enzyme digestion with Hin FI at Wageningen University.

\section{Statistical analysis}

Differences between mean values of descriptive parameters in the three studies were tested using one-way ANOVA. As the distribution of the folate intake data was skewed Spearman correlation coefficients were calculated between dietary intakes assessed with the FFQ and blood concentrations of folate and tHcy. Folate intake was categorised in quartiles and we investigated whether mean folate concentrations across quartiles showed a linear trend. Linear regression analysis was used to determine the best predictors of folate concentration. Erythrocyte or serum folate status was the dependent variable and folate intake, age, sex, MTHFR genotype, vitamin $\mathrm{B}_{12}, \mathrm{BMI}$, creatinine, alcohol intake and smoking were the independent variables. The choice for these confounders was based on previous literature ${ }^{20,21}$. For subjects from the FACIT-study only ( $n$ 803) there was a second measurement of folate intake, which was divided into quartiles as well to check the ability of the questionnaire to classify subjects into the same quartile of folate intake after 3 years. For this, Wilcoxon signed ranks test was used. Reproducibility of the FFQ was also assessed by calculation of the Spearman correlation coefficient between the first and second FFQ. Analyses were performed using SPSS (version 11.0 for Windows; SPSS Inc., Chicago, IL, USA).

\section{Results}

The mean age of the participants was 60 (SD 6) years (Table 1). Mean blood values were: tHcy 12.6 (SD 3.1) $\mu \mathrm{mol} / \mathrm{l}$, serum folate 12.8 (SD 4.4) $\mathrm{nmol} / \mathrm{l}$ and erythrocyte folate 661.3 (SD 263.9) nmol/l. Mean folate intake was 196 (SD 69) $\mu \mathrm{g} / \mathrm{d}$. Genotype frequencies of the MTHFR C677T polymorphism were in Hardy-Weinberg equilibrium; $15 \%$ of the participants were homozygous (TT), $45 \%$ were heterozygous (CT), $40 \%$ were of the wild type (CC). The participants of the three studies were not different in age, BMI, serum vitamin $\mathrm{B}_{12}$, MTHFR genotype and smoking behaviour. In the FACIT-study more men participated. As a possible consequence of the homocysteine inclusion criteria of the FACITstudy (tHcy concentrations $>13 \mu \mathrm{mol} / \mathrm{l}$ ), tHcy and creatinine concentrations were higher and serum and erythrocyte folate concentrations were lower in this study than in the other two studies, even though folate intake was $10-16 \%$ higher. Alcohol intake was significantly lower in the Dolfin study $(P<0.05)$.

Table 2 shows the correlations between folate intake and the blood concentrations of folate and tHcy, per study, for men and women separately, and per MTHFR C677T genotype. Correlations were generally weak. Correlations between folate intake and serum folate were higher than correlations between folate intake and erythrocyte folate concentrations. Correlations were similar when adjusted for confounders (unpublished results). As expected tHcy and serum folate $(r-0.37, P<0.01)$ and tHcy and erythrocyte folate $(r-0.28, P<0.01)$ were inversely related and serum and erythrocyte folate were strongly correlated $(r 0.51$, $P<0 \cdot 01)$.

There was a significantly increased serum folate concentration with increasing intake of folate $(P<0 \cdot 001)$. The increase in erythrocyte folate concentration over quartiles of folate intake did not reach significance $(P=0 \cdot 30$; Table 3$)$.

Table 4 shows that, in linear regression, folate intake, sex and MTHFR genotype were the strongest determinants of serum folate concentrations (standardised $\beta$ : $0.15,0.14$ and -0.13 respectively) and that alcohol intake was the strongest determinant of erythrocyte folate concentrations (standardised $\beta: 0 \cdot 15)$. 
Table 1. Characteristics of the study populations

(Mean values and standard deviations)

\begin{tabular}{|c|c|c|c|c|c|c|c|c|}
\hline & \multicolumn{2}{|c|}{ Total $(n 1281)$} & \multicolumn{2}{|c|}{ FACIT $(n 819)$} & \multicolumn{2}{|c|}{$\mathrm{CHEF}(n 157)$} & \multicolumn{2}{|c|}{ Dolfin(n 305) } \\
\hline & Mean & SD & Mean & SD & Mean & SD & Mean & SD \\
\hline Age (years) & $60 \cdot 2$ & $5 \cdot 6$ & $60 \cdot 2$ & 5.6 & $60 \cdot 0$ & 5.5 & $60 \cdot 2$ & $6 \cdot 0$ \\
\hline $\mathrm{BMI}(\mathrm{kg} / \mathrm{m} 2)$ & $26 \cdot 5$ & 3.6 & $26 \cdot 6$ & 3.6 & $26 \cdot 2$ & 3.5 & $26 \cdot 6$ & $3 \cdot 7$ \\
\hline Sex (\% M:F) & \multicolumn{2}{|c|}{$67: 33$} & \multicolumn{2}{|c|}{$72: 28^{*}$} & \multicolumn{2}{|c|}{$58: 42$} & \multicolumn{2}{|c|}{$59: 41$} \\
\hline THсу $(\mu \mathrm{mol} / /)$ & $12 \cdot 6$ & $3 \cdot 1$ & $13 \cdot 3^{*}$ & 2.9 & $10 \cdot 9^{\star}$ & $2 \cdot 8$ & $11 \cdot 6^{\star}$ & $3 \cdot 0$ \\
\hline Serum folate $(\mathrm{nmol} / \mathrm{l})$ & $12 \cdot 8$ & 4.4 & 12.5 & 4.4 & $14 \cdot 3$ & $4 \cdot 4^{\star}$ & $12 \cdot 9$ & $4 \cdot 2$ \\
\hline Erythrocyte folate (nmol/l) & $661 \cdot 3$ & 263.9 & $623 \cdot 2^{*}$ & $265 \cdot 0$ & 727.4 & 234.9 & 731.4 & 254.5 \\
\hline Serum vitamin B12 (pmol//l) & $318 \cdot 8$ & $168 \cdot 4$ & $320 \cdot 3$ & 191.9 & $316 \cdot 3$ & 87.9 & $316 \cdot 0$ & $128 \cdot 0$ \\
\hline Serum creatinine $(\mu \mathrm{mol} / \mathrm{l})$ & 88.0 & $13 \cdot 9$ & $92 \cdot 6^{*}$ & $12 \cdot 3$ & $83 \cdot 7^{\star}$ & $12 \cdot 1$ & $77 \cdot 8^{*}$ & $12 \cdot 8$ \\
\hline MTHFR genotype (\% CC:CT:TT) & \multicolumn{2}{|c|}{$40: 45: 15 \dagger$} & \multicolumn{2}{|c|}{$38: 46: 15$} & \multicolumn{2}{|c|}{ - } & \multicolumn{2}{|c|}{ 43:43:14 } \\
\hline Folate intake $(\mu \mathrm{g} / \mathrm{d})$ & 196 & 69 & $207^{\star}$ & 77 & 186 & 48 & 174 & 49 \\
\hline Alcohol intake $(\mathrm{g} / \mathrm{d})$ & 15 & 15 & 16 & 15 & 17 & 16 & $14^{*}$ & 15 \\
\hline Current smokers (\%) & 19 & & 20 & & 17 & & 16 & \\
\hline
\end{tabular}

$M$, male; F, female; THcy, total homocysteine.

Mean values were significantly different from the other studies: ${ }^{*} P<0.05$ (ANOVA).

$\dagger n 1120$.

Reproducibility could only be assessed in the FACIT-study. The mean estimated folate intakes on the first occasion (206 (SD 76) $\mu \mathrm{g} / \mathrm{d}$ ) were significantly higher compared to estimated folate intakes after 3 years of intervention (191 (SD 62) $\mu \mathrm{g} / \mathrm{d}), \quad P<0.0001$. The Spearman correlation coefficient between the two folate intakes was $0.58(P<0.01)$. Of the participants $47 \%$ were classified in the same quartile on both occasions, $31 \%$ were classified in a lower quartile and $22 \%$ in a higher quartile.

\section{Discussion}

We developed a FFQ to assess folate intake over the past 3 months in Dutch elderly people and compared the folate intake data with blood folate concentrations. We observed a weak positive correlation between folate intakes estimated with the FFQ and serum folate concentrations, but not erythrocyte folate. The FFQ classified $47 \%$ of the participants in the same quartile of folate intake after 3 years.
We validated the FFQ against biochemical markers of food intake. An advantage of using biomarkers is that they provide an objective measure of nutrient intake whose measurement errors are essentially independent of the errors associated with dietary intake measures based on self-report ${ }^{22}$. Biomarkers however are influenced by a number of physiologic, environmental, genetic and lifestyle factors ${ }^{23}$, and that is one of the reasons why correlations between intake and biomarkers are usually modest. Blood folate levels may be influenced by the amounts of polyglutamyl and monoglutamyl folates in the foods ${ }^{10}$, smoking ${ }^{24}$, chronic alcohol consumption $^{25}$, MTHFR genotype ${ }^{26}$ and certain drugs ${ }^{27}$. In our study it might be that the homogeneous population attenuated the correlations as well. Folate intake also has a large withinperson variation. As biomarkers are not a measure of absolute intake one can only test whether a questionnaire is suitable for ranking persons according to their consumption. In our study folate intake did not correlate with erythrocyte folate but with serum folate, similar to previous studies. Previous studies

Table 2. Crude Spearman correlation coefficients between folate intake and serum and erythrocyte folate concentrations and total homocysteine (tHcy)

\begin{tabular}{|c|c|c|c|c|c|c|}
\hline & \multirow[b]{2}{*}{ Total } & \multicolumn{2}{|c|}{ Sex } & \multicolumn{3}{|c|}{ MTHFR genotype } \\
\hline & & Men & Women & $\mathrm{CC}$ & $\mathrm{CT}$ & $\mathrm{TT}$ \\
\hline & \multicolumn{6}{|c|}{ FACIT $(n$ 819) } \\
\hline Serum folate & $0.16 \dagger$ & $0.20 \dagger$ & 0.12 & $0.19 \dagger$ & $0 \cdot 13^{*}$ & $0.21^{*}$ \\
\hline Erythrocyte folate & $0.11 \dagger$ & $0 \cdot 10^{*}$ & 0.10 & 0.10 & $0 \cdot 11^{\star}$ & 0.09 \\
\hline \multirow[t]{2}{*}{ tHcy } & -0.05 & $-0.08^{*}$ & -0.02 & -0.06 & -0.02 & $-0 \cdot 18^{*}$ \\
\hline & \multicolumn{6}{|c|}{ CHEF $(n 157)$} \\
\hline Serum folate & $0 \cdot 17^{*}$ & -0.01 & $0.40 \dagger$ & - & - & - \\
\hline Erythrocyte folate & 0.02 & -0.09 & 0.08 & - & - & - \\
\hline \multirow[t]{2}{*}{ tHcy } & 0.08 & 0.19 & -0.19 & - & - & - \\
\hline & \multicolumn{6}{|c|}{ Dolfin ( $n$ 305) } \\
\hline Serum folate & $0 \cdot 14^{*}$ & $0.26 \dagger$ & 0.02 & $0 \cdot 16$ & $0 \cdot 16$ & 0.06 \\
\hline Erythrocyte folate & 0.07 & 0.14 & -0.05 & -0.05 & 0.07 & 0.19 \\
\hline \multirow[t]{2}{*}{ tHcy } & $-0 \cdot 10$ & $-0.26 \dagger$ & 0.03 & $-0.19^{*}$ & -0.06 & -0.07 \\
\hline & \multicolumn{6}{|c|}{ Total $(n 1281)$} \\
\hline Serum folate & $0.14 \dagger$ & $0 \cdot 19 \dagger$ & $0 \cdot 11^{*}$ & $0.19 \dagger$ & $0 \cdot 12 \dagger$ & $0.16^{*}$ \\
\hline Erythrocyte folate & 0.05 & 0.07 & 0.00 & 0.04 & 0.06 & 0.06 \\
\hline tHcy & 0.02 & -0.04 & 0.04 & -0.02 & 0.02 & -0.09 \\
\hline
\end{tabular}

* Significantly different from $0, P<0.05$.

† Significantly different from $0, P<0.01$. 
Table 3. Estimated serum and erythrocyte folate concentrations by quartile of total folate intake

\begin{tabular}{|c|c|c|c|c|c|c|c|}
\hline \multirow[b]{2}{*}{ Folate intake $(\mu \mathrm{g} / \mathrm{d})$} & \multirow[b]{2}{*}{$n$} & \multicolumn{3}{|c|}{ Serum folate $(\mathrm{nmol} / \mathrm{l})$} & \multicolumn{3}{|c|}{ Erythrocyte folate $(\mathrm{nmol} / \mathrm{l})$} \\
\hline & & Mean & $95 \% \mathrm{Cl}$ & $P$ for trend & Mean & $95 \% \mathrm{Cl}$ & $P$ for trend \\
\hline$<153(133)$ & 320 & 11.9 & $11 \cdot 4,12 \cdot 3$ & & $639 \cdot 8$ & $610 \cdot 4,669 \cdot 2$ & \\
\hline $153-186(170)$ & 320 & $12 \cdot 4$ & $12 \cdot 0,12 \cdot 8$ & & 644.7 & $617.6,671.9$ & \\
\hline $186-225(204)$ & 321 & $13 \cdot 3$ & $12 \cdot 8,13 \cdot 8$ & & 674.6 & $646 \cdot 2,703 \cdot 0$ & \\
\hline$>225(261)$ & 320 & $13 \cdot 6$ & $13 \cdot 0,14 \cdot 1$ & $<0.001$ & 685.5 & $654 \cdot 4,716.5$ & 0.308 \\
\hline
\end{tabular}

that determined correlations between serum folate concentrations and folate intake estimated by a FFQ found correlation coefficients of $0.38^{28}, 0.34$ (crude) and $0 \cdot 61$ (adjusted) ${ }^{29}$, $0.06^{30}, 0.42^{31}$ and $0.13^{32}$. Previous studies that determined correlations between erythrocyte concentrations and folate intake found correlations coefficients of $0.25^{28}, 0.08^{30}$ and $0 \cdot 20^{31}$. Thus compared to other studies our correlations were moderate/low, but still significantly positive for serum folate. This could be explained by the fact that serum folate reflects recent intake and erythrocyte folate reflects longterm intake ${ }^{33}$ and with our FFQ food intake of the previous 3 months was assessed. Within-person variation of serum concentrations over time might also play a role; repeated blood measurements for all blood parameters would have been better to overcome this. In this study only blood parameters in the CHEF-study and erythrocyte folate in the FACITstudy were measured in duplicate, though this did not improve correlations. Although expected, MTHFR genotype did not modify the correlations between intake of folate and serum or erythrocyte folate.

In the linear regression model the main prognostic factors (folate intake, creatinine, vitamin $\mathrm{B}_{12}$, alcohol and MTHFR) were as expected; however, the determinants which best predicted folate concentrations in the blood were different for serum folate and erythrocyte folate. This may be explained by the fact that in the erythrocyte model most of the prognostic variables were not statistically significant, probably because the variation in the distribution was greater. For MTHFR an explanation might also be that in subjects with the TT genotype the association of dietary folate with erythrocyte folate is found to be stronger, compared to subjects with the CC or CT genotypes. In contrast, this is not the case for serum folate. The higher levels of erythrocyte folate in subjects with the TT genotype could be due to the difference in folate derivative composition between the genotypes and the different sensitivities of their chemical detection ${ }^{34}$. Furthermore, the fact that the models did not predict as well as in other populations is likely a consequence of the populations under study. We had strict screening criteria for age and for tHcy levels. The tHcy screening most likely indirectly excluded individuals with higher folate status which may have weakened the prognostic variables.

There are different methods to assess habitual food intake and the advantages and disadvantages associated with each method are well documented ${ }^{35-38}$. In studies like ours FFQ are the preferred method of dietary assessment as they are easy to administer and inexpensive to process. A general disadvantage of the FFQ is that the validity is highly dependent on the correct selection of the foods on the list ${ }^{36}$. Compared to other lists that often include twice as many food items our eighty-nine-item list was relatively short. However, it still covered at least $80 \%$ of the average folate intake. It has been shown that estimates of fruit and vegetable intake are related to the number of questions asked; the more questions asked, the more intake is over reported ${ }^{39}$. In studies like ours, where the intake of specific items or nutrients is of interest, a common practice to correct for this over-reporting is to include a summary question (how often do you eat ... (a food category)?) preceding or following questions on intake of specific items within a food category ${ }^{40}$. We also included a summary question for vegetables, fruits and alcohol intake, to reduce chances of over-reporting. In a study of Bogers

Table 4. Folate intake as a determinant of serum and erythrocyte folate concentrations by linear regression

\begin{tabular}{|c|c|c|c|c|c|c|}
\hline \multirow[b]{2}{*}{ Independent variables } & \multicolumn{3}{|c|}{ Serum folate concentration $(\mathrm{nmol} / \mathrm{l})$} & \multicolumn{3}{|c|}{ Erythrocyte folate concentration (nmol/l) } \\
\hline & B & Standardised B & $95 \% \mathrm{Cl}$ & B & Standardised $B$ & $95 \% \mathrm{Cl}$ \\
\hline Intercept & $10 \cdot 72$ & & $7 \cdot 11,14 \cdot 33$ & 519.45 & & $296.58,742.31$ \\
\hline Age (years) & 0.03 & 0.04 & $-0.01,0.08$ & -0.01 & 0.00 & $-2 \cdot 73,2 \cdot 71$ \\
\hline Sex $^{*}$ & $1.35^{\mathrm{a}}$ & 0.14 & $0.72,1.99$ & -5.01 & -0.01 & $-44.45,34.43$ \\
\hline BMI $\left(\mathrm{kg} / \mathrm{m}^{2}\right)$ & $-0.10^{b}$ & -0.08 & $-0.17,-0.03$ & 2.00 & 0.03 & $-2.34,6.34$ \\
\hline MTHFR $†$ & $-0.83^{a}$ & -0.13 & $-1.19,-0.47$ & 14.87 & 0.04 & $-7 \cdot 38,37 \cdot 12$ \\
\hline Serum $\mathrm{B}_{12}(\mathrm{pmol} / \mathrm{l})$ & 0.001 & 0.06 & $0.000,0.003$ & 0.05 & 0.03 & $-0.04,0.14$ \\
\hline Creatinine $(\mu \mathrm{mol} / \mathrm{l})$ & -0.001 & -0.003 & $-0.02,0.02$ & -0.57 & -0.03 & $-1 \cdot 86,0 \cdot 72$ \\
\hline Smoking & 0.08 & 0.02 & $-0.22,0.38$ & $16 \cdot 22$ & 0.05 & $-2 \cdot 23,34 \cdot 67$ \\
\hline Alcohol intake (g/d) & $0.02^{\mathrm{c}}$ & 0.07 & $0.002,0.04$ & $2 \cdot 77^{\mathrm{a}}$ & 0.15 & $1 \cdot 68,3.85$ \\
\hline Folate intake $(\mu \mathrm{g} / \mathrm{d})$ & $0.01^{\mathrm{a}}$ & 0.15 & $0.01,0.01$ & $0.22^{c}$ & 0.06 & $0.004,0.44$ \\
\hline
\end{tabular}

*Variable classification used for smoking: Never smokers $=0$, Current smokers $=1$, Ex-smokers $=2$.

† Variable classification used: MTHFR CC $=0$, MTHFR CT $=1$, MTHFR TT $=2$.

${ }^{a} P<0.001$.

${ }^{\mathrm{b}} P<0.01$

${ }^{\mathrm{c}} P<0.05$ 
et al. the summary question estimated vegetable intake better than the sum of the specific questions ${ }^{41}$. A kind of bias with one correction factor could be that all kinds of vegetables are similarly corrected, whereas possibly respondents could estimate some kinds of vegetables better than others. Furthermore, in FFQ inaccuracies in the estimation of portion sizes and the frequency of food consumption are often found ${ }^{35,31}$. This could also be a limitation of our study and could be overcome by administering the FFQ in conjunction with colour photographs of food portion sizes such as A Photographic Atlas of Food Portion Sizes ${ }^{42}$. Furthermore, FFQ rely on the respondent's self-description of his diet and it is also limited in its ability to assess accurately the nutrient intake of individuals or groups with dietary patterns markedly different from the food list ${ }^{37}$. It is difficult to overcome these problems when addressing the general population. Besides the quality of measurement of food intake the quality of food composition analysis is also important. There is a considerable, yet unidentified, difference between estimates of folate in foods analysed with HPLC methods which are 20-40\% lower compared with microbiological methods ${ }^{6}$.

Supplement users were excluded from our study and folic acid fortification is not allowed in the Netherlands; consequently most of the folate intake is probably derived from natural food products, so this could not affect the use of folate as a biomarker for folate intake of foods.

Reproducibility is generally determined by properties of the FFQ itself, respondent's memory and actual changes in food intake. Although reproducibility was still adequate for folate, 3 years is a long time interval to measure reproducibility. The respondent's memory will be of minor influence then and actual changes in diet are likely and cannot be separated from errors in measurement.

In conclusion, serum and not erythrocyte folate concentrations correlated positively with folate intake and the correlations were weaker than in other studies. Half the participants were classified into the same quartile and estimated folate intakes were comparable with other studies. This FFQ could provide a satisfying ranking according to folate intake of a Dutch elderly population.

\section{Acknowledgements}

We gratefully thank all study participants for their time and motivation. We thank the research teams for their dedication and enthusiasm. The research was supported by the Netherlands Organisation for Health Research and Development, Wageningen University and the Wageningen Centre for Food Sciences. Wageningen Centre for Food Sciences is an alliance of major Dutch food industries and knowledge institutes.

\section{References}

1. Herbert V (1967) Biochemical and hematologic lesions in folic acid deficiency. Am J Clin Nutr 20, 562-569.

2. MRC Vitamin Study Research Group (1991) Prevention of neural tube defects: results of the Medical Research Council Vitamin Study. Lancet 338, 131-137.
3. Clarke R, Smith AD, Jobst KA, Refsum H, Sutton L \& Ueland PM (1998) Folate, vitamin B12, and serum total homocysteine levels in confirmed Alzheimer disease. Arch Neurol 55, 1449-1455.

4. Choi SW \& Mason JB (2002) Folate status: effects on pathways of colorectal carcinogenesis. J Nutr 132, 2413S-2418S.

5. The Homocysteine Studies Collaboration (2002) Homocysteine and risk of ischemic heart disease and stroke. JAMA 288, 2015-2022.

6. Konings EJM, Roomans HHS, Dorant E, Goldbohm RA, Saris WHM \& van den Brandt, PA, (2001). Folate intake of the Dutch population according to newly established liquid chromatography data for foods. Am J Clin Nutr 73, 765-776.

7. Health Council of the Netherlands (2003) Dietary reference in Intakes: Vitamin B6, Folate and Vitamin B12. The Hague: Health Council of the Netherlands.

8. Durga J, Bots ML, Schouten EG, Kok FJ \& Verhoef P (2005) Low concentrations of folate, not hyperhomocysteinemia, are associated with carotid intima-media thickness. Atherosclerosis 179, 285-292.

9. van Oort FV, Melse-Boonstra A, Brouwer IA, et al. (2003) Folic acid and reduction of plasma homocysteine concentrations in older adults: a dose-response study. Am J Clin Nutr 77, 1318-1323.

10. Melse-Boonstra A, West CE, Katan MB, Kok FJ \& Verhoef P (2004) Bioavailability of heptaglutamyl relative to monoglutamyl folic acid in healthy adults. Am J Clin Nutr 79, 424.

11. The Netherlands Nutrition Centre. Zo eet Nederland, 1992. Resultaten van de Voedselconsumptiepeiling 1992 (Results of the national food consumption survey 1992). The Hague: Voorlichtingsbureau voor de Voeding (The Netherlands Nutrition Centre), 1993.

12. Brants HAM, Hulshof KFAM (1995) De ontwikkeling van een voedingsmiddelentabel met foliumzuurgehalten (Development of a table on folate contents in food). Zeist: TNO Voeding.

13. Holland B, Welch AA, Undin JD, Buss DH, Paul AA \& Southgate DAT (1991) McCance and Widdowson's the Composition of Foods. Cambridge: The Royal Society of Chemistry and Ministry of Agriculture, Fisheries and Food.

14. Brants HAM (2001) Ontwikkeling van een voedselfrequentievragenlijst naar de foliumzuurinneming van ouderen (Development of a food frequency questionnaire to assess folate intake in elderly). Zeist: TNO Voeding.

15. Hulshof KFAM, van der Heijden LJM, Donders-Engelen M (1992) Maten, gewichten en codenummers 1992 (Food portion sizes and coding instructions 1992). Zeist: TNO-Nutrition/ Agricultural University Wageningen.

16. Bouman M, Van Erp-Baart MA, Brants H, Bausch S (1998) Voedsel Frequentie Expert, de ontwikkeling van een geautomatiseerd systeem voor het maken van voedselfrequentievragenlijsten. Deel 1 - Functioneel ontwerp (Food Frequency Expert, development of a computerised system for the development of food frequency questionnaires. Part 1 - Functional design). Zeist: TNO Nutrition.

17. Brants HAM, Bouman M (1998) Voedsel Frequentie Expert, de ontwikkeling van een geautomatiseerd systeem voor het maken van voedselfrequentie vragenlijsten. Deel 4 - De gebruikershandleiding (Food Frequency Expert, development of a computerised system for the development of food frequency questionnaires. Part 4 - User manual). Zeist: TNO Voeding.

18. Bouman M, Brants HAM, Kistemaker C (2000) Vragenlijsten Verwerkingssysteem met SAS (SAS/Vovris). Deel 1 - Gebruikershandleiding (Questionnaire processing system with SAS (SAS/Vovris). Part 1 - User manual). Zeist: TNO Voeding.

19. NEVO (2001) NEVO-tabel. Nederlands Voedingssttoffenbestand 2001 (Dutch Nutrient Database 2001). The Hague: The Netherlands Nutrition Centre.

20. De Bree A, Verschuren WM, Kromhout D, Kluijtmans LA \& Blom HJ (2002) Homocysteine determinants and the evidence 
to what extent homocysteine determines the risk of coronary heart disease. Pharmacol Rev 54, 599-618.

21. Ueland PM, Refsum H, Beresford SA \& Vollset SE (2000) The controversy over homocysteine and cardiovascular risk. Am J Clin Nutr 72(2), 324-332.

22. van't Veer P, Kardinaal AF, Bausch-Goldbohm RA \& Kok FJ (1993) Biomarkers for validation. Eur J Clin Nutr 47, Suppl 2, S58-S63.

23. Hunter D (1998) Biochemical Indicators of Dietary Intake, 2nd ed. New York: Oxford University Press.

24. Senti FR \& Pilch SM (1985) Analysis of folate data from the second National Health and Nutrition Examination Survey (NHANES II). J Nutr 115, 1398-1402.

25. Herbert V (1990) Development of human folate deficiency. In Folic Acid Metabolism in Health and Disease, pp. 195-210 [MF Picciano, ELR Stokstad and JF Gregory, editors]. New York: Wiley-Liss.

26. de Bree A, Verschuren WM, Bjorke-Monsen AL, et al. (2003) Effect of the methylenetetrahydrofolate reductase 677C-T mutation on the relations among folate intake and plasma folate and homocysteine concentrations in a general population sample. Am J Clin Nutr 77, 687-693.

27. Roe DA (1990) Drug-folate interrelationships: historical aspects and current concerns. In Folic Acid Metabolism in Health and Disease, pp. 277-287 [MF Picciano, ELR Stokstad and JF Gregory, editors]. New York: Wiley-Liss.

28. Green TJ, Allen OB \& O'Connor DL (1998) A three-day weighed food record and a semiquantitative food-frequency questionnaire are valid measures for assessing the folate and vitamin B-12 intakes of women aged 16 to 19 years. J Nutr 128, 1665-1671.

29. Jacques PF, Sulsky SI, Sadowski JA, Phillips JCC, Rush D \& Willett WC (1993) Comparison of micronutrient intake measured by a dietary questionnaire and biochemical indicators of micronutrient status. Am J Clin Nutr 57, 182-189.

30. Drogan D, Klipstein-Grobusch K, Wans S, Luley C, Boeing H \& Dierkes J (2004) Plasma folate as marker of folate status in epidemiological studies: the European Investigation into Cancer and Nutrition (EPIC)-Potsdam study. Br J Nutr 92, 489-496.

31. Pufulete M, Emery PW, Nelson M \& Sanders TA (2002) Validation of a short food frequency questionnaire to assess folate intake. Br J Nutr 87, 383-390.
32. Brevik A, Vollset SE, Tell GS, et al. (2005) Plasma concentration of folate as a biomarker for the intake of fruit and vegetables: the Hordaland Homocysteine Study. Am J Clin Nutr 81, 434-439.

33. Crews H, Alink G, Andersen R, et al. (2001) A critical assessment of some biomarker approaches linked with dietary intake. Br J Nutr 86, Suppl 1, S5-S35.

34. Ozturk H, Durga J, van de Rest O \& Verhoef P (2005) The MTHFR 677 C-T genotype modifies the relation of folate intake and status with plasma homocysteine in middle-aged and elderly people. Ned Tijdschr Klin Chem Labgeneesk 30, 208-217.

35. Bingham SA, Gill C, Welch A, et al. (1994) Comparison of dietary assessment methods in nutritional epidemiology: weighed records v. $24 \mathrm{~h}$ recalls, food-frequency questionnaires and estimated-diet records. Br J Nutr 72, 619-643.

36. Bingham SA, Nelson M, Paul AA, Haralsdottir J, Loken AB \& van Staveren WA (1988) Methods for data collection at an individual level. In Manual on methodology for food consumption studies, pp. 53-106 [ME Cameron and WA van Staveren, editors]. New York: Oxford University.

37. Block G (1989) Human Dietary Assessment: Methods and Issues. Prev Med 18, 653-660.

38. Thompson FE \& Byers T (1994) Dietary Assessment Resource Manual. Nutr 124, 2245S-2317S.

39. Krebs-Smith SM, Heimendinger J, Subar AF, Patterson BH \& Pivonka E (1995) Using food frequency questionnaires to estimate fruit and vegetable intake: association between number of questions asked and total intakes. J Nutr Educ 27, $80-85$.

40. Haraldsdottir J (1993) Minimizing error in the field: quality control in dietary surveys. Eur J Clin Nutr 47, Suppl 2, S19-S24.

41. Bogers RP, Dagnelie PC, Westerterp KR, et al. (2003) Using a correction factor to correct for overreporting in a food-frequency questionnaire does not improve biomarker-assessed validity of estimates for fruit and vegetable consumption. $J$ Nutr 133, 1213-1219.

42. Nelson M, Atkinson M \& Meyer J (1997) A Photographic Atlas of Food Portion Sizes. London: Nutritional Epidemiology Group UK. 